\title{
ON A WEIGHTED GENERALIZATION OF IYENGAR TYPE INEQUALITIES INVOLVING BOUNDED FIRST DERIVATIVE
}

\author{
P. CERONE AND S. S. DRAGOMIR
}

Abstract. Inequalities are obtained for weighted integrals in terms of bounds involving the first derivative of the function. Quadrature rules are obtained and the classical Iyengar inequality for the trapezoidal rule is recaptured as a special case when the weight function $w(x) \equiv 1$. Applications to numerical integration are demonstrated.

Mathematics subject classification (1991): 26D15, 26D99, 41A55.

Key words and phrases: Hayashi and Iyengar inequalities, weighted quadrature.

\section{REFERENCES}

[1] R. P. Agarwal and S. S. Dragomir, An application of Hayashi's inequality for differentiable functions, Computers Math. Appl., 32(6) (1996), 95-99.

[2] D. S. Mitrinović, J. E. Pečarić and A. M. Fink, Classical and New Inequalities in Analysis, Kluwer Academic Publishers, 1993.

[3] D. S. Mitrinović, J. E. Pečarić and A. M. Fink, Inequalities for Functions and Their Integrals and Derivatives, Kluwer Academic Publishers, 1994.

[4] S. S. Dragomir and S. Wang, Applications of Iyengar's type inequalities to the estimation of error bounds for the trapezoidal quadrature rule, Tamkang Journal of Mathematics, 29(1) (1998), 55-58.

[5] S. S. Dragomir, Y. J. Cho and S. S. Kim, Some remarks on the Milanonvić-Pečarić Inequality and applications for special means and numerical integration, Tamkang Journal of Mathematics, to appear.

[6] P. Cerone and S. S. Dragomir, Lobatto type quadrature rules for functions with bounded derivative, Math. Inequal. Appl., to appear. 